\title{
Structural Design and Modelling Method for the Post-tensioned CLT Shear Wall Structures
}

\author{
Minjuan $\mathrm{He}^{1^{*}}$, Xiaofeng $\mathrm{Sun}^{2}$, and Zheng $\mathrm{Li}^{3}$ \\ ${ }^{1}$ Professor, Department of Structural Engineering, Tongji University \\ ${ }^{2}$ PhD candidate, Department of Structural Engineering, Tongji University \\ ${ }^{3}$ Associate Professor, Department of Structural Engineering, Tongji University \\ *Corresponding author's e-mail: hemj@tongji.edu.cn
}

\begin{abstract}
This paper presents the direct displacement-based design (DDD) procedure, structural modelling method, and structural performance calibration for post-tensioned CLT shear wall structures (PTCLTstrs). Numerical models of the post-tensioned (PT) CLT shear walls were developed and calibrated with the experimental results. Based on the developed shear wall models, parametric analysis were conducted to investigate the lateral performance influencing factors. Then, a DDD procedure was developed and demonstrated by the design examples of a set of 8-, 12-, and 16storey PT-CLTStrs. The corresponding simplified structural models were developed, and then a series of pushover and time-history dynamic analysis were conducted to calibrate the calculated structural performance objectives with the design targets of the DDD procedure. Finally, the empirical cumulative distribution functions (CDFs) of the maximum inter-storey drift (MaxISDR) were constructed. It is found that when the width of the PT CLT shear walls increases from $1.8 \mathrm{~m}$ to $3.0 \mathrm{~m}$, the base shear at the drift of $2.0 \%$ increases by twice accordingly. When the diameter of the PT strand increases from $15.2 \mathrm{~mm}$ to $34.6 \mathrm{~mm}$, the base shear at the drift of $2.0 \%$ increases by up to five times. Additionally, the MaxISDR limitation of the PTCLTStrs is recommended as $2.2 \%$ under the collapse prevention (CP) hazard level. The study results can serve as guidelines for the development of engineering design methods for the PTCLTStrs.
\end{abstract}

\section{KEYWORDS}

Direct displacement-based design procedure; Post-tensioned CLT shear wall; Parametric analysis; Simplified structural model; Inter-storey drift limitation

\section{INTRODUCTION}

Cross laminated timber (CLT), acting as one innovative engineering product, can provides similar mechanical properties in orthogonal directions, large in-plane strength, and ideal integrity. Such advantages make it suitable for shear walls of mid- or high-rising timber structures. An increasing number of studies have focused on CLT connections, CLT shear walls or floor diaphragm, and CLT structures. Popovski et al. (2010) investigated the influence of connection layouts, vertical loads atop the walls, and height-to-width ratio on the lateral performance of the CLT shear walls. Branco et al. (2015) tested five full-scale timber floors in order to assess the effectiveness of in-plane strengthening using CLT panels. For the CLT shear wall structures, 
Ceccotti et al. (2012) assessed the dynamic performance of one full-scale seven-storey CLT structure based on the shaking table test. Sun et al. (2018) investigated the inter-storey drift limitations under different earthquake hazard levels for a set of multi-storey CLT structures. For the aforementioned CLT shear walls, the lateral load-resisting mechanism often results in concentrated failure in the connections, and the ensuing degradation of the lateral stiffness and lateral load-resisting capacity of the entire shear walls. To improve the lateral performance and address the remaining issues (e.g., limited deformation capabilities, large base shear, excessive connections damage), in recent years one type of self-centering CLT shear walls post-tensioned to the foundation or floor diaphragm by the high-strength post-tensioned (PT) steel bars or strands were developed and studied (Ganey et al. (2017); He et al. (2018)). In this paper, a direct displacement-based design (DDD) procedure for the PT CLT shear wall structures (PT-CLTstrs) were developed, which was then illustrated by the design examples of a set of 8-, 12-, and 16storey PT-CLTStrs. Based on the design results, simplified structural models of the PT-CLTstrs were developed in OpenSees. Finally, the analytical structural performance objectives were calibrated with the design targets of the DDD procedure.

\section{SHEAR WALL MODEL VERIFICATION}

Three 0.5-scale PT CLT shear walls with different initial PT force were tested in Tongji University, China. Two 15.2-mm-diameter PT steel strands with yield strength of $1070 \mathrm{MPa}$ were incorporated into each of these walls. The corresponding ratios of the initial PT stress to the yield strength were $15.4 \%, 30.7 \%$, and $46.1 \%$, respectively. The detailed configurations of the PT CLT shear wall specimens were reported by He et al. (2018).

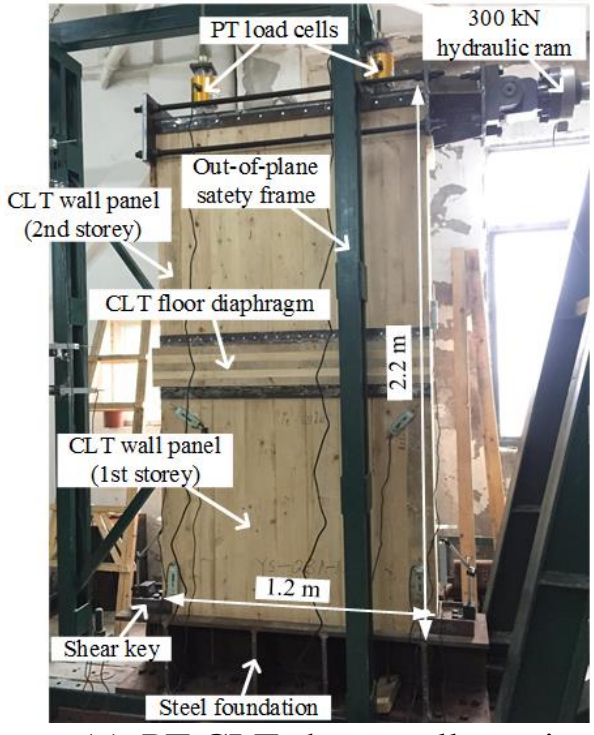

(a) PT CLT shear wall specimens

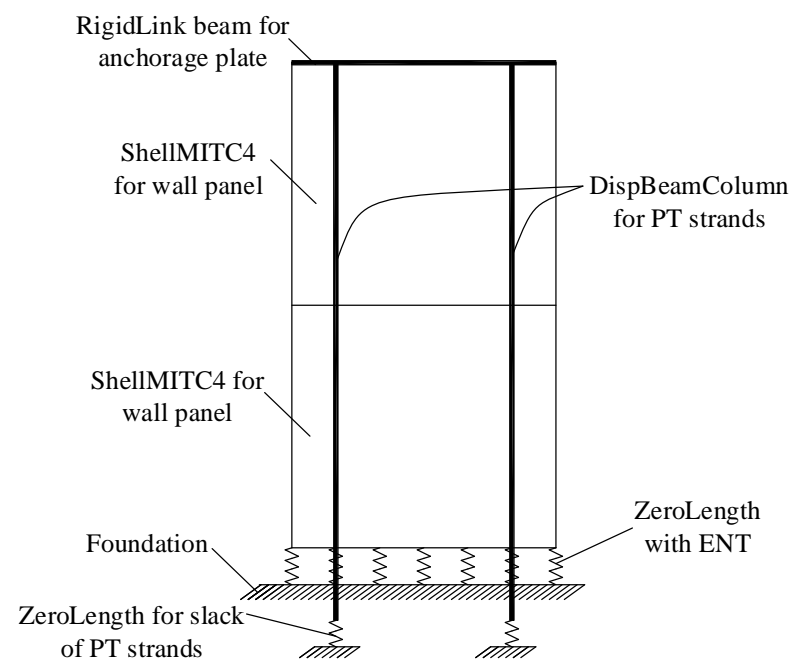

(b) Numerical model in OpenSees

Figure 1. The PT CLT shear wall specimens and the developed model

The numerical models for the PT CLT shear walls were developed in OpenSees and then calibrated with the corresponding experimental results. In such numerical models, the shellMITC4 element combined with the J2Plasticity material model was used to simulate the CLT panels. Zerolength element combined with the elastic-no-tension (ENT) model was used to simulate the compressive stiffness of the contact surface between the wall panels and the 
foundation. The displacement-based-beam-column (DispBeamColumn) element combined with Steel02 material model was used to simulate the PT strands. The models Zerolength elements combined with Steel01 model were defined between the bottom nodes of the PT strands and the foundation. The CLT material properties defined in the models were in accordance with the tests conducted by He et al. (2018). The wall specimens and the developed model are shown in Figure 1. The analytical curves from the un-scaled wall models were calibrated with the experimental curves, which had taken the scale ratio of the displacement and that of the base shear force (i.e., 0.5 and 0.25) into account. Good agreement can be observed between the experimental results and the analytical results, as shown in Figure 2.
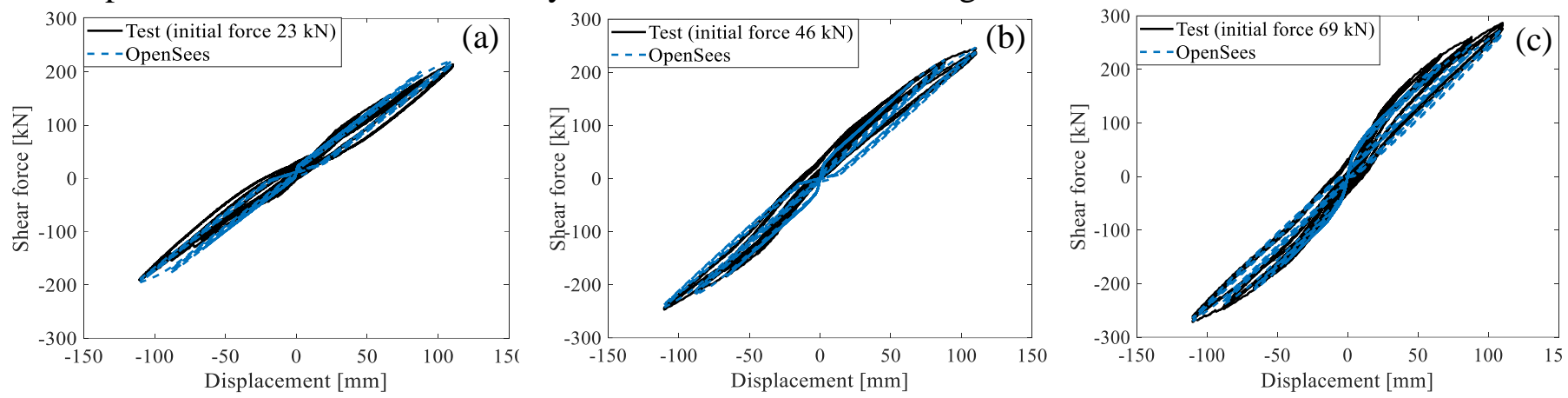

Figure 2. Wall model calibration: (a) $23 \mathrm{kN}$ initial force; (b) $46 \mathrm{kN}$ initial force; (c) $69 \mathrm{kN}$ initial force;

\section{PARAMETRIC ANALYSIS}

Based on the calibrated PT CLT shear wall models, parametric analysis was conducted to investigate the influence of the height-to-width ratio and that of the diameter of PT strand on the lateral performance of the shear walls. The width of wall model was set as $1.8 \mathrm{~m}, 2.4 \mathrm{~m}$, and 3.0 $\mathrm{m}$. According to the common diameter specifications from the Chinese code NSACRD (2015), the diameter of the PT strand defined in the wall model was set as $15.2 \mathrm{~mm}, 17.8 \mathrm{~mm}, 21.8 \mathrm{~mm}$, $26.2 \mathrm{~mm}, 30.4 \mathrm{~mm}$, and $34.6 \mathrm{~mm}$. Since a drift of $2.0 \%$ was recommended as the drift limitation for the PT-CLTstrs under maximum credible event (MCE) scenario according to a capacity demand spectrum (Chopra et al. (1999)), the base shear force of the 2-storey PT CLT shear walls at the drift of $2.0 \%$ was obtained, as listed in Table 1. It is found that the base shear of the PT CLT shear walls at the drift of $2.0 \%$ increases significantly with the increase of the diameter of the PT strands, the initial PT stress ratio, or the width of the CLT panels. When the width of the PT CLT shear walls increases from $1.8 \mathrm{~m}$ to $3.0 \mathrm{~m}$, the base shear at the drift of $2.0 \%$ increases by twice accordingly. When the diameter of the PT strand increases from $15.2 \mathrm{~mm}$ to $34.6 \mathrm{~mm}$, the base shear at the drift of $2.0 \%$ increases by up to five times.

Table 1. Base shear force at the drift of $2.0 \%$ (unit in $\mathrm{kN}$ )

\begin{tabular}{cccccccccc}
\hline Diameter of & \multicolumn{1}{c}{$15.4 \%$ initial PT stress ratio } & \multicolumn{2}{c}{$30.7 \%$ initial PT stress ratio } & \multicolumn{3}{c}{$46.1 \%$ initial PT stress ratio } \\
\cline { 2 - 11 } strands $(\mathrm{mm})$ & $1.8-\mathrm{m}$ & $2.4-\mathrm{m}$ & $3.0-\mathrm{m}$ & $1.8-\mathrm{m}$ & $2.4-\mathrm{m}$ & $3.0-\mathrm{m}$ & $1.8-\mathrm{m}$ & $2.4-\mathrm{m}$ & $3.0-\mathrm{m}$ \\
\hline 15.2 & 38.59 & 56.53 & 76.03 & 46.40 & 69.0 & 95.71 & 51.75 & 81.58 & 114.6 \\
\hline 17.8 & 59.19 & 84.65 & 109.8 & 69.9 & 105.8 & 141.8 & 75.71 & 117.7 & 164.8 \\
\hline 21.8 & 88.29 & 126.0 & 164.4 & 102.9 & 152.2 & 204.9 & 113.0 & 169.8 & 236.7 \\
\hline 26.2 & 123.1 & 176.0 & 228.2 & 141.8 & 208.4 & 281.3 & 155.6 & 232.2 & 321.8 \\
\hline 30.4 & 148.9 & 209.4 & 279.2 & 167.9 & 246.9 & 338.6 & 185.6 & 275.0 & 380.3 \\
\hline 34.6 & 200.2 & 279.8 & 374.9 & 229.0 & 318.1 & 434.7 & 241.9 & 357.4 & 490.8 \\
\hline
\end{tabular}




\section{PROPOSED DIRECT DISPLACEMENT-BASED DESIGN PROCEDURE}

The proposed direct displacement-based design (DDD) procedure is illustrated for a set of 8-, 12, and 16-storey PT CLT shear wall structures (PT-CLTStrs). The structures were assumed located in Sichuan, China, and the height of each storey was assumed as $2.6 \mathrm{~m}$. The soil condition was selected as type II (average shear wave velocity of the upper $30 \mathrm{~m}$ of the side profile $\left(V_{30}\right)$ was $\left.280 \mathrm{~m} / \mathrm{s} \sim 480 \mathrm{~m} / \mathrm{s}\right)$. The floor layout is shown in Figure 3 . According to the results of gravity load analysis, a constant floor weight of 246.6 tons and a roof weight of 204.1 tons were obtained. The details of each step in the DDD procedure are provided as followed.

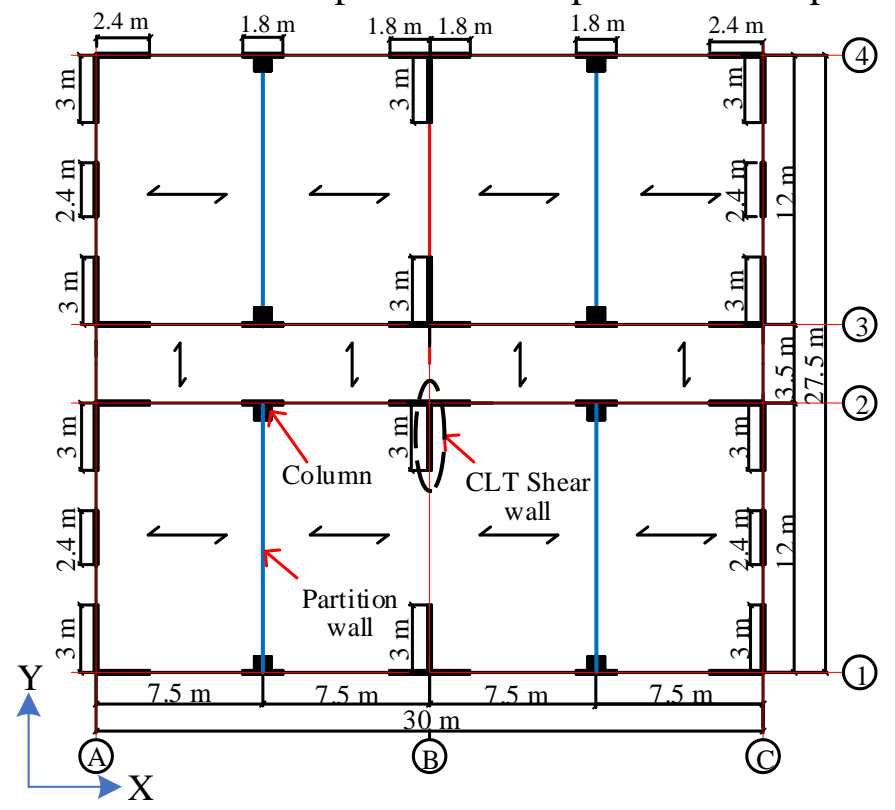

Figure 3. Configuration of the prototype PT CLT shear wall structures

(1) Define performance level: The 50-year exceedance probability for the earthquakes corresponding to Collapse Prevention (CP) hazard level that was defined in the ASCE code $A S C E / S E I 41$ (2013) is $2 \%$ within an average return period of 2475 years. Additionally, according to the Chinese technical specification JGJ 3 (2010), it was recommended to implement seismic design under $\mathrm{CP}$ hazard level for novel structural buildings with a total height of $24 \mathrm{~m}$ or more. According to Sarti et al. (2015), the drift limitation of CP was recommended as $2.0 \%$ for the PT-CLTStrs, which was adopted as the trail inter-storey drift.

(2) Substitute equivalent single degree of freedom (SDOF) system: The design displacement $\left(\Delta_{d}\right)$, effective mass ( $\left.m_{\text {eff }}\right)$, and effective height $\left(h_{e f f}\right)$ of the substitute equivalent SDOF system can be calculated using Equations (1) (3) provided by Sullivan and Lago (2012), where $m_{i}$ is the lumped mass in each storey, $h_{i}$ is the height of each storey from the base, and $\Delta_{i}$ is the target displacement at level $i$ relative to the base of each floor. $\Delta_{i}$ can be estimated using Equations (4) and (5) provided by Sullivan et al. (2010), where $H_{n}$ is the total height of the structure, $\omega_{\theta}$ is a reduction factor accounting for higher-mode effects, and $\theta_{c}$ is the trial inter-storey drift target.

$$
\begin{aligned}
\Delta_{d} & =\frac{\sum_{i=1}^{n} m_{i} \Delta_{i}^{2}}{\sum_{i=1}^{n} m_{i} \Delta_{i}} \\
m_{\text {eff }} & =\frac{\sum_{i=1}^{n} m_{i} \Delta_{i}}{\Delta_{d}}
\end{aligned}
$$




$$
\begin{gathered}
h_{e f f}=\frac{\sum_{i=1}^{n} m_{i} \Delta_{i} h_{i}}{\sum_{i=1}^{n} m_{i} \Delta_{i}} \\
\Delta_{i}=\omega_{\theta} \theta_{c} h_{i}\left(\frac{4 H_{n}-h_{i}}{4 H_{n}-h_{1}}\right) \\
\omega_{\theta}=1.15-0.0034 H_{n} \leq 1
\end{gathered}
$$

(3) Estimate the equivalent viscous damping (EVD): To estimate the hysteretic damping of the PT-CLTStr, the aforementioned shear wall models listed in Table 1 were used to conduct the cyclic analysis in OpenSees. The hysteretic damping was calculated based on the concept proposed by Jacobsen (1960). Taking the trail inter-storey drift of $2.0 \%$ into consideration, the hysteretic damping was adopted as $1.2 \%$ (Figure 4). The elastic damping was considered as 4.6 $\%$ based on the shaking table test on CLT structures conducted by Ceccotti et al. (2013). Therefore, the equivalent viscous damping ratio of the PT-CLTstrs was adopted as $5.8 \%$, which was then defined in the structural models for the dynamic analysis.

(4) Create the displacement spectrum: According to equation (6), the acceleration spectrum, $\mathrm{S}_{\mathrm{A}}$, (taking the EVD of $5.8 \%$ into consideration) can be transformed into the displacement spectrum, $\mathrm{S}_{\mathrm{D}}$. The required period, $T_{\text {eff, }}$, can be obtained by locating the point on the displacement spectrum for governing the displacement, which corresponded to the target displacement, $\Delta_{d}$. The corresponding $T_{\text {eff }}$ of the 8-, 12-, and 16-storey PT-CLTstrs obtained as $2.1 \mathrm{~s}, 2.6 \mathrm{~s}$, and 3.05 $\mathrm{s}$, respectively, as shown in Figure 5.

$$
S_{D}=\frac{T^{2}}{4 \pi^{2}} S_{A}
$$

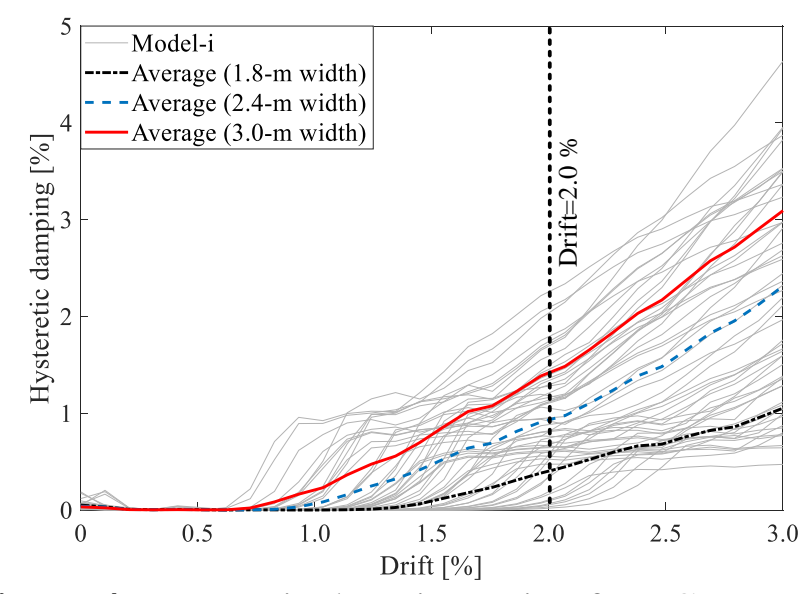

Figure 4. Hysteretic damping ratio of PT CLT walls

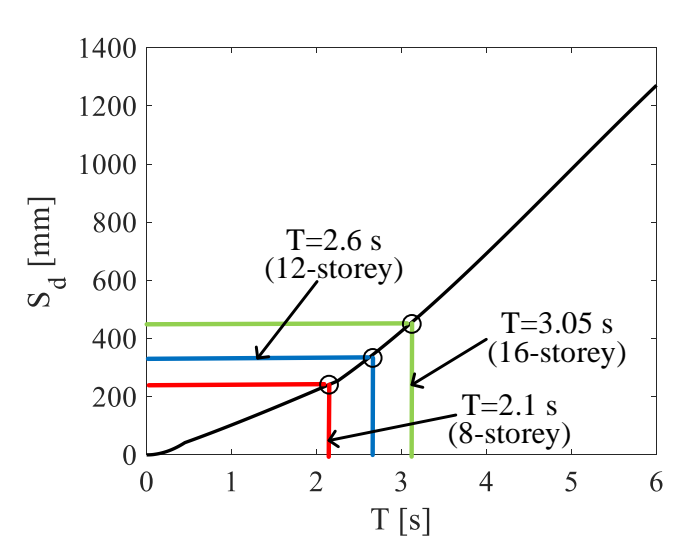

Figure 5. Displacement spectral

(5) Estimate and distribute the base shear force: The effective stiffness $\left(K_{\text {eff }}\right)$ and the base shear force $\left(V_{b}\right)$ of the SDOF systems were calculated based on Equations (7) - (8). Then, the estimated design base shear force was distributed in proportion with the target displacement at level $i\left(\Delta_{i}\right)$ using Equation (9). Finally, the total design shear force at storey $i\left(V_{i, \text { total }}\right)$ of each structure was calculated.

$$
\begin{gathered}
K_{e f f}=\frac{4 \pi^{2}}{T_{e f f}} \\
V_{b}=K_{e f f} \times \Delta_{d}
\end{gathered}
$$




$$
F_{i}=V_{b} \frac{m_{i} \Delta_{i}}{\sum_{i=1}^{n} m_{i} \Delta_{i}}
$$

(6) Shear wall selection: For each individual storey, the shear wall configurations were selected to have a larger total wall resistance than the total design shear force $\left(V_{i, \text { total }}\right)$. The total wall resistance is namely the total design base shear of the walls (i.e., the base shear at the trial interstorey drift target listed in Table 1) belonging to storey $i$.

(7) Develop simplified structural model: In the simplified three-dimensional model, the twoNodeLink element was combined with linear material model with the same elastic modulus as the initial lateral stiffness of one certain PT CLT shear wall, to simulate the elastic lateral performance of the shear wall and that of the PT-CLTstrs. Such an elastic model was used to identify the direction of the first-order mode and obtained the corresponding fundamental period. It was found that first-order mode of all the structural models was translational mode along the $\mathrm{Y}$ direction. The fundamental periods (i.e., $1.97 \mathrm{~s}, 2.40 \mathrm{~s}$, and $2.99 \mathrm{~s}$ for the 8-, 12-, and 16-storey PT-CLTstrs, respectively) were slightly less than the corresponding required periods of the DDD procedure. The PT CLT shear walls distributed along the A axis were obtained from the entire three-dimensional PT-CLTStr; thus, forming one two-dimensional PT CLT shear wall structural model (Figure 6), which was used to evaluate the seismic performance of the PT-CLTStr in the Y direction. The floor weight and the roof weight of the two-dimensional PT CLT shear wall structure were approximately a quarter of the entire three-dimensional PT-CLTStr's weight (i.e., 61.65 tons and 51.03 tons, respectively).

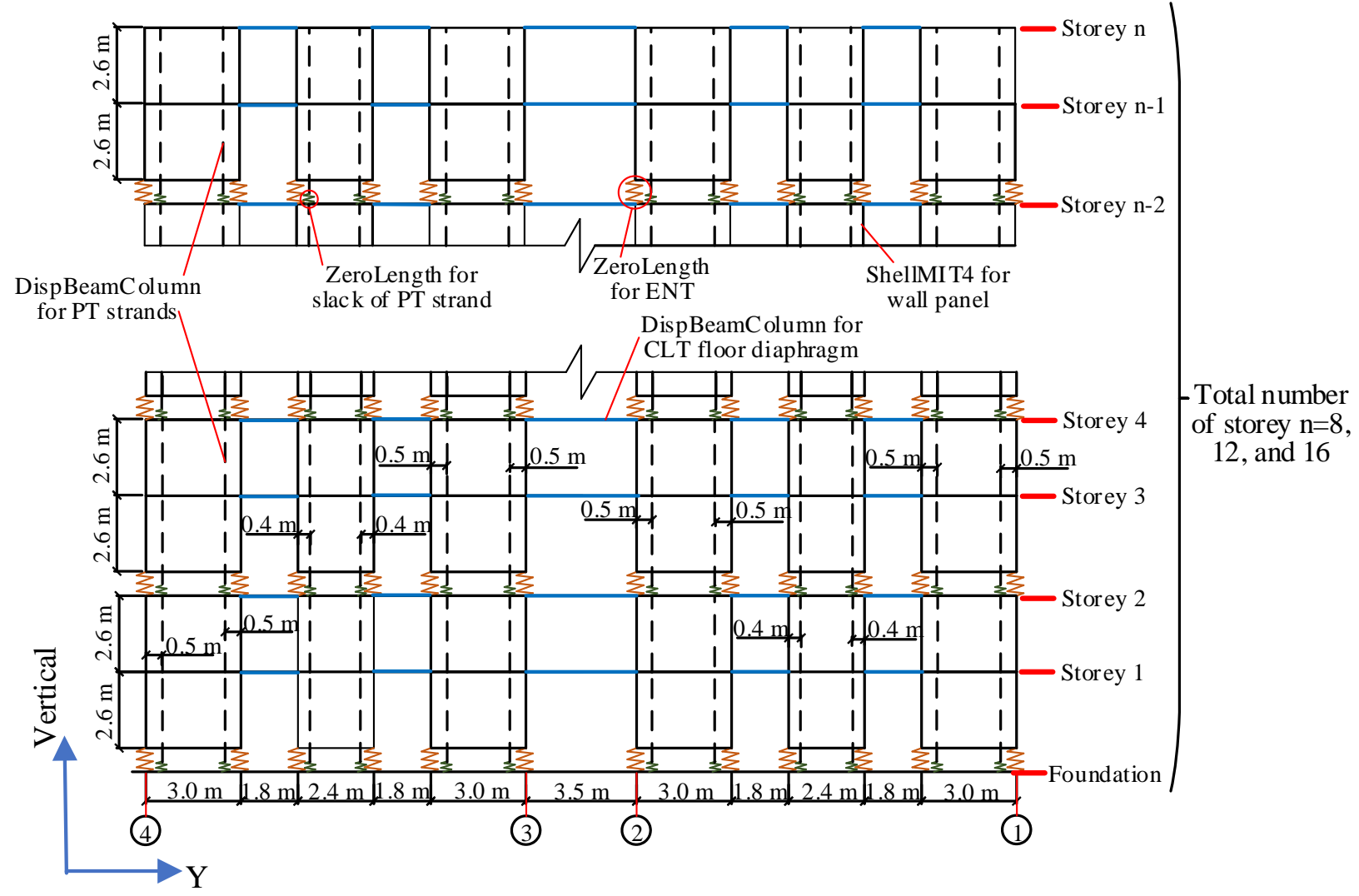

Figure 6. Model of the PT-CLTstrs (two-dimentional)

(8) Check the structural model: In the two-dimensional models (Figure 6), the CLT floor diaphragm was defined between the PT CLT shear walls in each floor using the 
DispBeamColumn elements. The theoretical initial lateral stiffness provided by the PT CLT shear walls distributed along the A axis can be estimated by multiplying the proportion of their total initial lateral stiffness by the total effective stiffness of the DDD procedure, which was estimated as $6000 \mathrm{kN} / \mathrm{m}, 5416 \mathrm{kN} / \mathrm{m}$, and $4870 \mathrm{kN} / \mathrm{m}$ for the two-dimensional plane structural models of the 8-, 12-, and 16-storey PT-CLTstrs. Further analysis was then proceeded on the twodimensional plane structural models, during which the effective width of the DispBeamColumn elements for the floor diaphragm was adjusted until the initial lateral stiffness of each model was close to the corresponding theoretical initial lateral stiffness. The effective width of the DispBeamColumn elements were finally calibrated as $0.62 \mathrm{~m}, 2.05 \mathrm{~m}$ and $4.75 \mathrm{~m}$ for the models of the 8-, 12-, and 16-storey PT-CLTstrs, respectively. The drift limitation of each model under the CP hazard level was estimated through a series of nonlinear time history analyses. For each structural model, 20 un-scaled ground motion records ( $V_{30}$ was between $280 \mathrm{~m} / \mathrm{s}$ and $480 \mathrm{~m} / \mathrm{s}$ ) matching the modified target response spectrum with the corresponding fundamental period were selected as the input excitations. Figure 7 shows the response spectrum of the ground motions selected for the 16-storey PT-CLTstr as an example. The CDF curves of the peak inter-storey drift were formed (Figure 8). Based on the $95 \%$ probability of non-exceedance (PNE), the drift limitations under CP hazard level can be obtained as $2.0 \%, 2.2 \%$, and $2.4 \%$ approximately for 12-, 8-, and 16-storey PT-CLTstrs, respectively. The average value of drift limitations is $2.2 \%$, which is much close to the trial inter-storey drift target of the DDD procedure.

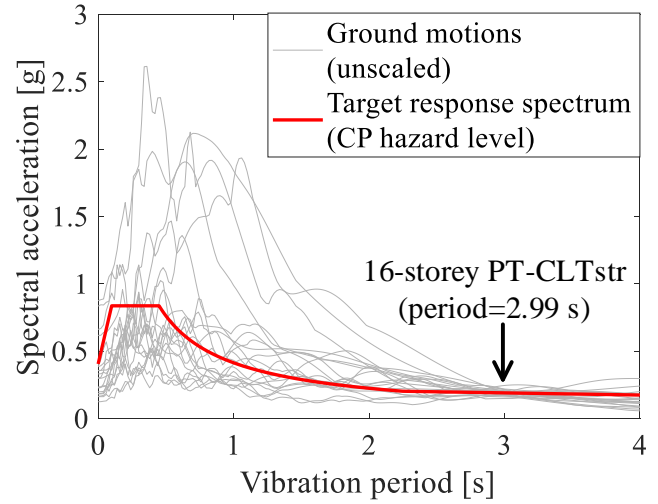

Figure 7. Response spectrum (16-storey PT-CLTstr)

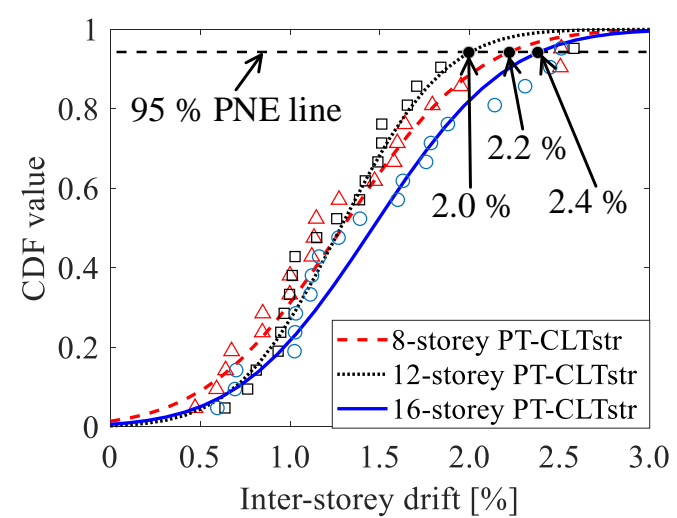

Figure 8. The CDFs of peak inter-storey drift

\section{CONCLUSION}

In this paper, the DDD procedure and the modelling method of the PT-CLTstrs were presented. Based on the parametric analysis, the quantitative relationships between the base shear of the PT CLT shear walls and the influencing factors (i.e., the width of the wall, the diameter of the strand, and the initial post-tensioning stress ratio) are provided. Additionally, the inter-storey drift limitation of the PT-CLTstrs under CP hazard level is defined as $2.2 \%$, based on the CDF curves of the peak inter-storey drift.

\section{ACKNOWLEDGEMENTS}

The authors also gratefully acknowledge the support from National Natural Science Foundation of China (Grant NO. 51778460) and China Scholarship Council (Grant NO. 201706260124). 
MOC SUMMIT / MAY 2019

\section{REFERENCES}

ASCE (American Society of Civil Engineers). (2013). "Seismic evaluation and retrofit of existing buildings." ASCE/SEI 41-13, Reston, Va, USA.

Branco, J.M., Kekeliak, M., and Lourenco, P.B. (2015). "In-plane stiffness of timber floors strengthened with CLT." European Journal of Wood and Wood Products, 73(3), 313-323.

Ceccotti A, Sandhaas C, Okabe M, Yasumura M, Minowa C, Kawai N. (2013) "SOFIE project3D shaking table test on a seven-storey full-scale cross-laminated building." Earthquake Engineering \& Structural Dynamics, 42(13), 2003-2021.

Ceccotti, A., Sandhaas, C., Okabe, M., Yasumura, M., Minowa, C., and Kawai, N. (2012). "SOFIE project- 3D shaking table test on a seven-storey full-scale cross-laminated building." Earthquake Engineering \& Structure Dynamics, 42(13), 2003-2021.

Chopra A.K, Goel, R.K. (1999) "Capacity-demand-diagram methods based on inelastic design spectrum.” Earthquake Spectral, 15(4), 637-656.

Ganey, R., Berman, J., Akbas, T., Loftus, S., Daniel Dolan, J., Sause, R., Ricles, J., Pei, S.L., van de Lindt, J., and Blomgren, H.E. (2017). "Experimental investigation of self-centering cross-laminated timber walls." Journal of Structure Engineering, 04017135.

He M.J, Sun X.F, and Li Z. (2018) "Bending and compressive properties of cross-laminated timber (CLT) made from Canadian hemlock." Construction and Building Materials, 185, 175-183.

He M.J, Sun X.F, and Li Z. (2018) "Experimental performance of post-tensioned rocking singlepanel CLT walls." Proceedings of the 10th World Conference on Timber Engineering, Trees and Timber Institute, Paper No. S218. Seoul, Korea.

Jacobsen LS. (1960) "Damping in composite structures. Proceedings of the 2nd World Conference on Earthquake Engineering.” Tokyo, Japan.

MOHURD (Ministry of Housing and Urban-Rural Development of the People's Republic of China). (2010). "Technical specification for concrete structures of tall buildings." JGJ 32010, Beijing, China. (in Chinese)

NSACRD (National Standardization Administration Committee of the People's Republic of China). (2015). "Steel strand for pre-stressed concrete." GB/T 5224, Beijing, China. (in Chinese).

Popovski, M., Schneider, J., and Schweinsteiger, M. (2010). "Lateral load resistance of crosslaminated wood panels." Proceedings of World Conference on Timber Engineering, Trees and Timber Institute, Natural research council, Riva del Garda, Italy.

Sarti F, Palermo A, Pampanin S. (2015) "Quasi-static cyclic testing of two-thirds scale unbonded post-tensioned rocking dissipative timber walls." Journal of Structural Engineering, 142(4), E4015005.

Sullivan T, Priestley M, Calvi, G. (2010) "Introduction to a model code for displacement-based seismic design." Advances in Performance-Based Earthquake Engineering, 137-148.

Sullivan TJ, Lago A. (2012) "Towards a simplified direct DBD procedure for the seismic design of moment resisting frames with viscous dampers." Engineering Structures, 35, 140-148.

Sun, X.F., He, M.J., and Li, Z. (2018). "Performance evaluation of multi-storey cross-laminated timber structures under different earthquake hazard levels." Journal of Wood Science, 64(1), 23-39. 